\title{
Study on Damage Characteristics of Fiber Concrete under Acid Rain Erosion
}

\author{
Duo $\mathrm{Wu}^{* 1}$ \\ ${ }^{1}$ Department of Civil Engineering, Nanchang Institute of Technology, Nanchang Jiangxi 330029, China
}

\begin{abstract}
Concrete structure will be corroded under acid rain scouring and soaking for a long time, which has a great influence on its durability life. In order to further study the damage characteristics of fiber reinforced concrete under acid rain erosion, the formation mechanism of acid rain and its influence on the corrosion and deterioration of concrete and fiber materials were analyzed in this paper. Taking basalt fiber concrete as an example, the characteristics such as porosity, compressive strength and mechanical indexes were studied and analyzed. Moreover, the reasons for the optimal fiber content was briefly analyzed. The results show that the inner structure of basalt concrete mixed with $0.1 \%$ fiber was the most stable and the corrosion resistance was the most satisfying. This conclusion has certain reference significance for the corrosion damage research of fiber reinforced concrete.
\end{abstract}

\section{Introduction}

The durability damage of structure caused by natural environment is a prominent factor restricting the current engineering structure life. Among the causes of durability damage of concrete, such as corrosion, freezethaw and carbonization, acid rain, as a typical source of erosion, is one of the current hot research directions in structural durability damage[1-2]. Under long-term acid rain scouring and acid solution soaking, various types of geotechnical structures such as houses, bridges and dams in acid rain areas will suffer varying degrees of damage. In recent years, with the development of technology, various fiber materials are also widely used in engineering structures. Although the application of new materials has improved the load-bearing capacity and performance of the structure under conventional conditions, the impact of new materials on the structure in various harsh climates and environments still needs to be explored urgently[3].

\section{Analysis of the Influence of Acid Rain Erosion on Fiber Concrete}

\subsection{Acid Rain Formation Mechanism}

Precipitation with a PH less than 5.6 is commonly referred to as acid rain, and its formation comes mainly from the burning of fossil fuels. $\mathrm{SO}_{3}, \mathrm{NO}_{\mathrm{X}}$ and other products produced from the combustion of fossil fuels can combine with water molecules in the rain, snow, hail and other precipitation forms to form acid deposits, which are the main forms of acid rain[4].

$$
\left\{\begin{array}{c}
\mathrm{C}_{x} \mathrm{H}_{y} \mathrm{~S}_{z}+n \mathrm{O}_{2} \rightarrow z \mathrm{SO}_{2}+x \mathrm{CO}_{2}+y \mathrm{H}_{2} \mathrm{O} \\
4 \mathrm{FeS}_{2}+11 \mathrm{O}_{2} \rightarrow 2 \mathrm{Fe}_{2} \mathrm{O}_{3}+8 \mathrm{SO}_{2}
\end{array}\right.
$$

According to the above cause analysis, the formation of acid rain can be analyzed from both the natural environment and the social environment. From the perspective of the natural environment, acid rain is mainly affected by factors such as topographic differences, soil types, climate characteristics and vegetation; from the perspective of social environment, a large amount of coal and other fossil energy will be consumed every year, from which oxides $\mathrm{SO}_{2}$ and other gases represented by sulfur will also directly lead to the formation of acid rain. The chemical reaction mechanism of sulfide combustion is as follows:

\subsection{Degradation Analysis of Material Corrosion}

Fiber concrete materials are mainly composed of cement, mortar or matrix concrete, steel fiber, polypropylene fiber and other additional fibers. Under the action of acid rain scouring and infiltration in the natural environment, the mortar layer on the surface of the structure and various types of fibers inside will be damaged and degraded to different degrees. Especially in recent years, due to the changes in global climate characteristics and the influence of human activities, the regional soil acidification has become more severe, which has further aggravated the corrosion and deterioration of soil structures. For fiber reinforced concrete, its degradation is mainly manifested as follows:

(1)Deterioration of Concrete Matrix Materials

$\mathrm{Ca}^{2+}$ in concrete has good stability and alkalinity in conventional environment, which is helpful for it to withstand various loads. However, a large amount of

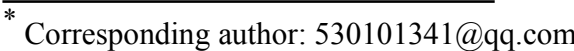


acidic ions such as $\mathrm{H}^{+}$and $\mathrm{SO}_{4}{ }^{2-}$ contained in acid rain can neutralize and react with $\mathrm{Ca}^{2+}$ in concrete in water and humid environments. On the one hand, the reaction of $\mathrm{H}^{+}$in acid rain with $\mathrm{Ca}(\mathrm{OH})_{2}$ in concrete will weaken the performance of concrete surface. On the other hand, the reaction of acidic ions such as $\mathrm{SO}_{4}{ }^{2-}$ in acid rain with alkaline substances in concrete will produce a certain amount of bulky substances such as ettringite and gypsum. These bulky substances will also increase the internal stress of the concrete, causing bulges in the matrix, thus accelerating the appearance of cracks, resulting in a decrease in the strength and performance of the concrete [5].

(2)Influence of Fiber Material on Deterioration of Concrete Matrix

Various kinds of fibers added to the concrete matrix, such as steel fiber, polypropylene fiber, basalt fiber, etc., can have a certain enhancement effect on the impermeability, frost resistance, carbonization resistance, erosion resistance, durability, tensile and compression toughness of concrete [6]. Wang Yan et al. [7] carried out acid rain cycle test of steel fiber concrete under bending load and studied the mechanical properties of steel fiber material's performance degradation under the action of acid rain. The test results show that the addition of steel fiber can significantly reduce the erosion rate of concrete under the action of bending tensile stress, especially when the steel fiber content is $1.5 \%$. Lu Shasha et al. [8] studied the influence of steel fiber content in coal gangue concrete, $\mathrm{PH}$ value of acid rain and other factors on various durability indexes based on acid rain cyclic erosion test. The experimental results show that $1 \%$ steel fiber content can optimize the pore structure of concrete, improve its compactness, inhibit the influence of acid rain solution on the carbonization depth and resistance of concrete matrix, and effectively improve its comprehensive performance. The experimental results of Liu Yun [9] also indicate that the incorporation of trace basalt fiber had an effect on acid rain corrosion.

\section{RESEARCH ON PERFORMANCE DEGRADATION UNDER ACID RAIN EROSION}

\subsection{Porosity Analysis}

Under the erosion of acid rain, the porosity change in concrete structure is an important manifestation of its deterioration and damage. Taking basalt fiber concrete as an example, the acid corrosion resistance of different fiber content was studied. The corrosion resistance test of plain concrete, plain concrete mixed with $0.05 \%$, $0.1 \%, 0.2 \%$ and $0.3 \%$ fiber was carried out for $0 \sim 180 \mathrm{~d}$ ages and the change of porosity is shown in Figure 1.

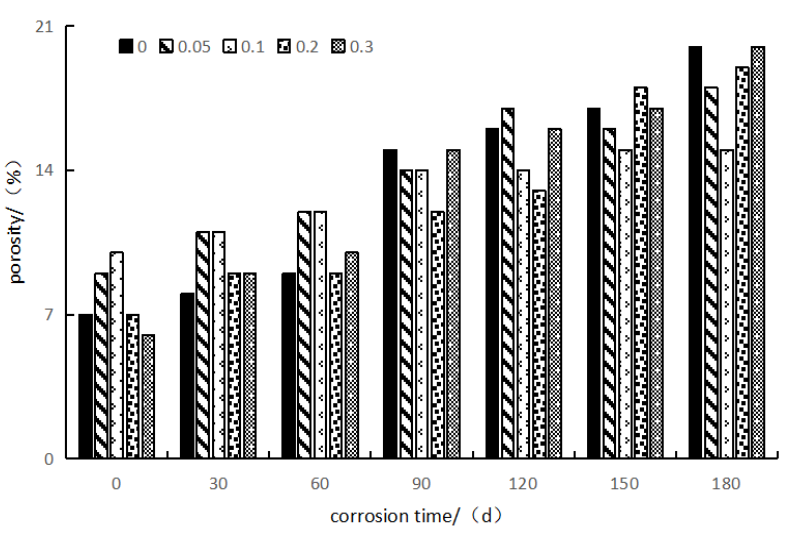

Figure 1. The porosity change of fiber concrete at $0 \sim 180 \mathrm{~d}$ ages

According to the porosity change shown in Figure 1, the porosity inside the material increased in a linear trend with the increase of age. This phenomenon indicates that under long-term erosion of simulated acid rain solution, all kinds of cracks and porosity of fiber concrete were further enlarged due to the corrosion of acid ions. From the perspective of fiber content, the influence of different fiber content on the development of porosity was slightly different. In order to further study the variation of porosity under different fiber content, the variation and development of porosity and corrosion time at $0 \sim 90 \mathrm{~d}$ and $0 \sim 180 \mathrm{~d}$ ages under different fiber content is listed in Table 1 and Table 2.

Table 1. Comparison of fitting relationship between porosity and corrosion time of $0 \sim 90 \mathrm{~d}$ ages

\begin{tabular}{|c|c|c|c|}
\hline $\begin{array}{c}\text { Fiber } \\
\text { volume } \\
\text { ratio/\% }\end{array}$ & 0 90d age & Fitness $\mathbf{R}^{2} / \%$ & Slope K \\
\hline 0 & $n=0.083 T+6$ & 80.65 & 0.083 \\
\hline 0.05 & $n=0.053 T+9.1$ & 98.46 & 0.053 \\
\hline 0.1 & $n=0.043 T+9.8$ & 96.57 & 0.043 \\
\hline 0.2 & $n=0.05 T+7$ & 88.24 & 0.05 \\
\hline 0.3 & $n=0.093 T+5.8$ & 93.33 & 0.093 \\
\hline
\end{tabular}

As can be seen from Table 1, there was a certain difference in the relationship between porosity and time change of different fiber content, and the value of slope $\mathrm{K}$ could reflect the rate of porosity change to a certain extent. With the increase of fiber volume ratio, the porosity decreased first and then increased. When the fiber content was $0.3 \%$, the porosity change was the largest and the corrosion resistance was poor; when the fiber content was $0.1 \%$, the porosity change was the smallest and the corrosion resistance was the best. 
Table 2. Comparison of fitting relationship between porosity and corrosion time of $0 \sim 180 \mathrm{~d}$ ages

\begin{tabular}{|c|c|c|c|}
\hline $\begin{array}{c}\text { Fiber volume } \\
\text { ratio/\% }\end{array}$ & 0 180d age & Fitness $\mathbf{R}^{\mathbf{2}} / \%$ & Slope $\mathbf{K}$ \\
\hline 0 & $n=0.076 T+6.3$ & 94.46 & 0.076 \\
\hline 0.05 & $n=0.05 T+9.4$ & 94.23 & 0.05 \\
\hline 0.1 & $n=0.03 T+10.3$ & 93.01 & 0.03 \\
\hline 0.2 & $n=0.069 T+6.2$ & 94.07 & 0.069 \\
\hline 0.3 & $n=0.076 T+6.4$ & 96.6 & 0.076 \\
\hline
\end{tabular}

Further considering the longer age, compared with the $0-90 \mathrm{~d}$ age, the comparison results of $0-180 \mathrm{~d}$ age shown in Table 2 also show the development rule that the porosity changes first decreased and then increased with the increase of fiber ration. However, the corresponding slope $\mathrm{K}$ value was smaller, indicating that with the increase of age, the change rate of porosity in the later stage was slower than that in the earlier stage. It can also be found that when the fiber content was $0.1 \%$, the porosity change was the smallest and the corrosion resistance was the best.

\subsection{Compressive Property Analysis}

Long-term erosion of acid rain solution will cause damage to the structure and affect its compressive strength. The above-mentioned test data of fiber concrete were further analyzed to investigate the relationship between corrosion age and compressive strength. The compressive strength of fiber concrete at $90 \mathrm{~d}, 180 \mathrm{~d}$ and 270d is shown in Figure 2.

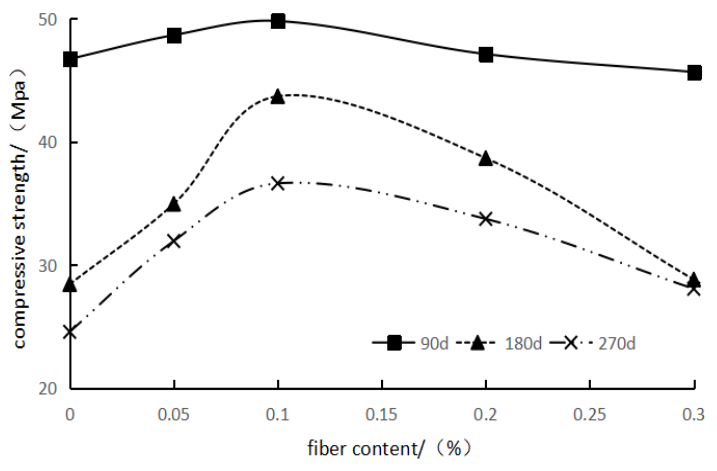

Figure 2. Comparison of compressive strength of fiber concrete at different ages

As can be seen from Figure 2, with the increase of age, the compressive strength of fiber concrete presented an overall downward trend, reflecting that the corrosion of acid solution would reduce the compressive strength of fiber concrete. By comparing the fiber content, it can be found that the fiber content also had a certain influence on its compressive strength. Within the range of $0 \% \sim 0.3 \%$ of , its compressive strength generally increased first and then decreased. When the fiber content was $0.1 \%$, its compressive strength reached its maximum, and the difference would be further enlarged with the increase of corrosion age.

Figure 3 shows the comparison of the compressive strength of fiber concrete under acid solution erosion and water soaking at $90 \mathrm{~d}$ and $180 \mathrm{~d}$ ages.

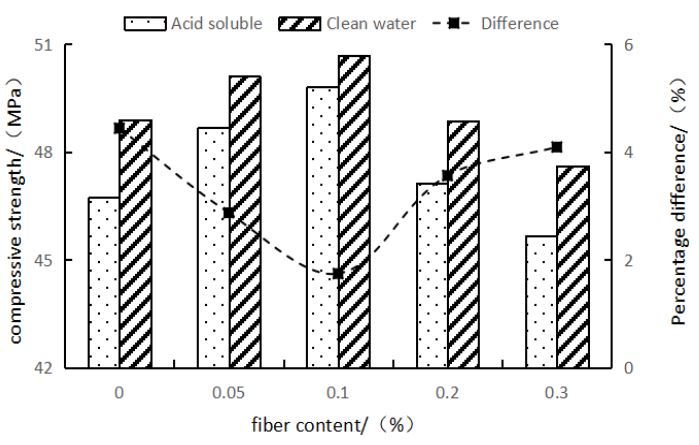

(a) compressive strength comparison at $90 \mathrm{~d}$

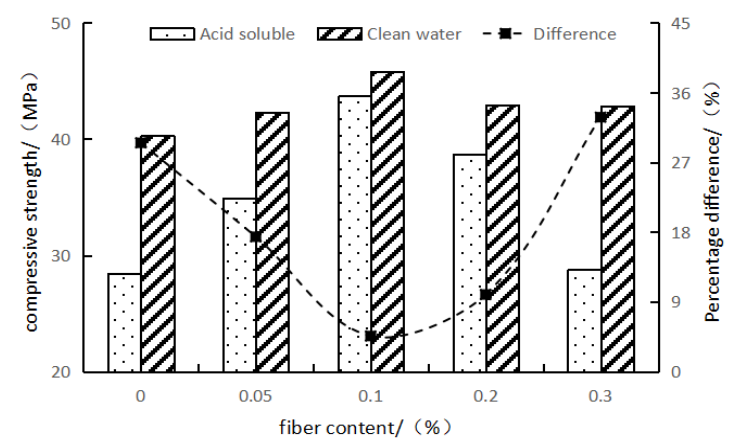

(b) compressive strength comparison at $180 \mathrm{~d}$

Figure 3. Influence of acid rain solution at different ages on the compressive strength of fiber reinforced concrete

According to the comparison of $90 \mathrm{~d}$ compressive strength in Figure 3 (a), the acid solution had a certain weakening effect on the compressive strength of fiber concrete. Within the range of $0 \% \sim 0.3 \%$ fiber content, the compressive strength decreased by about $2 \% \sim 5 \%$, and when the fiber content was $1 \%$, the compressive strength decreased the least. The results of $180 \mathrm{~d}$ compressive strength in Figure 3 (b) further verified this rule, and with the increase of erosion time, the weakening of compressive strength was further intensified, reaching about $5 \% \sim 33 \%$. It shows that with the increase of corrosion time, the gap of the weakening of compressive strength caused by the difference of fiber content was further enlarged. However, when the fiber content was $1 \%$, its compressive strength changed little, indicating better corrosion resistance.

\section{Reason Analysis of Optimal Fiber Content}

Based on the above analysis results, it can be seen that adding fiber into concrete can improve its corrosion resistance to a certain extent, but this result does not 
increase linearly. With the increase of fiber content, its corrosion resistance tends to increase first and then decrease, and its corrosion resistance will reach the best under a certain fiber content. For different fiber types and durability indicators, the corresponding mixing amount is often quite different, which needs specific analysis as shown in Figure 4.

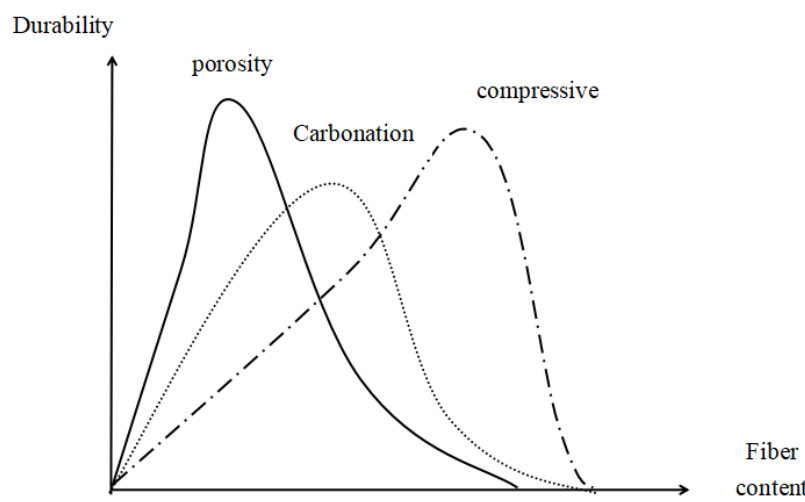

Figure 4. Typical parameter diagram affecting the corrosion resistance of fiber reinforced concrete

\section{Conclusion}

In this paper, the damage characteristics of fiber concrete under the action of acid rain were studied and the following conclusions were drawn:

1.Under the acid rain erosion, the damage of fiber concrete materials is mainly manifested by the deterioration of the concrete matrix material and the variation in resistance of different fiber materials.

2.The influence of acid rain erosion can be basically reflected by change of structure porosity. For basalt fiber concrete, under the long-term immersion of acid solution, the fiber content with a volume ratio of $0.1 \%$ had the smallest porosity change and the smallest corrosion damage.

3. Compressive strength is one of the important mechanical indexes of the structure. Under the long-term immersion of acid solution, the change of compressive strength of basalt fiber with a content of $1 \%$ was still small, showing a strong corrosion resistance.

\section{Acknowledgments}

This work was partially supported by the Research Project of Jiangxi Provincial Department of Education (GJJ190980).

\section{References}

1. Cao C.,Zheng S S.,Hu W B.(2019)A Survey on Concrete Structure Properties Under Acid Rain Erosion. Materials Reports., 33(6):1869-1874.

2. Li B X.,Qian X.,Wang K.(2019)Performance Degradation Law of Concrete under Coupling Effects of Acid Rain and Freeze-Thaw
Cycles.Bulletin
of the
Chinese

Ceramicsociety.,38(11):3559-3564.

3. WU D.,TENG Y X.Research status and prospect of durability of steel-polypropylene fiber reinforced concrete(2019).Journal of Nanchang Institute of Technology.,38(4):23-28.

4. Zheng L Y.,Chen Z A.,Zhang L.,Chen Y Q.,Hong X O.,SHI H X.(2020)Characteristics and Variation Trends of Acid Rain in Chengdu during 20062017.Meteorological Science and Technology. 48(3):380-386.

5. NIU J G.(2008)Concrete Neutralization in the Atmospheric EnvironmentBased on Multi-factor Effects.Xi'an University of architecture and technology,Xi'an.

6. Gao D Y.,Liu J X.(1994)Basic theory of steel fiber reinforced concrete.Science and Technology Literature Press, Beijing.

7. Wang Y.,Niu D T.,Song Z P.(2014)Durability of Steel Fiber Reinforced Concrete Under Combined Effect of Flexural Loading and Acid Rain Erosion.Materials Reports., 28(12):120-124.

8. Lu S S.,Ma F H.,Liu S X.(2016)Durability of Steel Fiber Reinforced Coal Gangue Concrete under Acid Rain.Non-Metallic Mines,39(6):60-62.

9. Liu Y.(2017)Study on Erosion Test and Mechanism of Basalt Fiber Concrete.Xi'an University of Technology,Xi'an. 